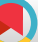

\title{
Predictors of Pap Smear Screening Behavior Among Rural Women in Tabriz, Iran: An Application of Health Belief Model
}

\author{
Towhid Babazadeh ${ }^{1}$, Saber Ghaffari-Fam (iD ${ }^{2,}{ }^{*}$, Shahram Oliaei ${ }^{3}$, Ehsan Sarbazi ${ }^{4}$, Arash Shirdel ${ }^{5}$, \\ Parvin Mostafa-Gharabaghi ${ }^{2}$ and Hosein Azizi ${ }^{6}$ \\ ${ }^{1}$ Department of Public Health, Sarab Faculty of Medical Sciences, Sarab, Iran \\ ${ }^{2}$ Women's Reproductive Health Research Center, Tabriz University of Medical Sciences, Tabriz, Iran \\ ${ }^{3}$ Center of Submarine and Hyperbaric Medicine, Health Deputy of the Iranian Navy, Tehran, Iran \\ ${ }^{4}$ Ahar Health Center, Tabriz University of Medical Sciences, Tabriz, Iran \\ ${ }^{5}$ Department of Health Management and Economics, School of Public Health, Tehran University of Medical Sciences, Tehran, Iran \\ ${ }^{6}$ Department of Epidemiology and Biostatistics, School of Health, Tehran University of Medical Sciences, Tehran, Iran \\ "Corresponding author: Road Traffic Injury Research Center, Tabriz University of Medical Sciences, Tabriz, Iran. Email: ghaffari.s68@gmail.com
}

Received 2018 December 09; Revised 2019 April 07; Accepted 2019 April 16.

\begin{abstract}
Background: In order to increase the acceptance level of the cervical cancer screening behavior among women, understanding the associated factors of the behavior is necessary.

Objectives: The aim of this study was to evaluate the cognitive determinants of Pap smear screening (PSS) behaviors among rural women in Tabriz, Iran.

Methods: In this cross sectional study, multistage random sampling was employed to recruit 220 rural women in Tabriz, Iran. A valid and reliable health behavior model (HBM)-based instrument was completed by all the respondents.

Results: The odds ratio of perceived benefits in multivariable was $1.18(1.08-1.27)$ i.e. with one unit increase in perceived benefits, odds cervical cancer screening behavior $18 \%$ increases, and age $=0.94(0.91-0.98)$ i.e. with one unit increase in age, odds cervical cancer screening behavior $6 \%$ decreases were statistically significant.

Conclusions: The HBM was promising in determining the cognitive predictors of PSS behavior. Healthcare providers may specifically focus on perceived benefits and perceived barriers for designing PSS promotion interventions.
\end{abstract}

Keywords: Health Behavior, Rural Health, Papanicolaou Test

\section{Background}

Cervical cancer is the second most common cancer to affect women over the world with 527,624 new cases and 265,672 deaths reports, annually (1). According to recently published data, each year, more than 400,000 cases may be diagnosed in the world comprising approximately $12 \%$ of the most commonly diagnosed caners among women (2). Cervical cancer is also one of the most common neoplasms among women both in low and middle-income countries (3). In other words, approximately, $90 \%$ of cervical cancer deaths occur in low and middle-income regions like Sub-Saharan Africa, Latin America, and the Caribbean (4). It is estimated that the incidence proportion of cervical neoplasm in Iran is 2.4 per 100,000 per year women (5).

Several risk factors may contribute in developing the disease such as early marriage, sexual relations before the age of 18 , frequent marriage history, multiple pregnancies and childbirth, smoking, immunosuppressive diseases as well as low socioeconomic status, and genital infections like human papillomavirus (HPV), which is a sexually transmitted infection (6). Currently, Pap smear screening of cervical cancer has been one of the most successful public health measures over the last decade (3). In addition to the low cost, the test has high potential of early stage cervical cancer detection in women looking normal (7).

It has been reported that the Pap test can reduce the incidence rate and the mortality rate of cervical cancer by $79 \%$ and $70 \%$, respectively (8). Thus, Pap smear screening exam may be considered as a cheap tool to early detection and primary prevention of cervical malignancies (9). Despite the significant success of the test in detecting cervical cancer, the participation rate in developing countries is only $5 \%$, while in the high-income countries like the U.S., the corresponding proportion is about 90\% (10). In Iran, several studies $(11,12)$ have also reported the low participation rate for the test. For instance, Farzaneh et al. in Ardabil, Iran indicated that $27.1 \%$ of the women referred to the 
comprehensive health services centers had the history of Pap smear uptake (11).

One of the reasons for the low participation rate of the test may be due to the lack of awareness about its importance. Therefore, informing the women about the importance and effectiveness of early diagnosis of cervical neoplasm could be important steps in promoting the participation rate at the national scale (13). However, before an early detection intervention for Pap smear uptake, there is a necessity for identifying the factors related to and the barriers correlated with the behavior.

Since the theory-based interventions provide an appropriate structure to develop and have a guide for evaluation, they are more effective in influencing health-related behaviors compared to the non-theoretical approaches (14, 15). Researchers have applied some models for changing the health behaviors. Health belief model (HBM) (Figure 1) is one of the most appropriate models in the field of changing health behaviors. Public health services to forecast the health-promoting behaviors, such as uptake of screening programs. This model, as a comprehensive model, is based on people's motivation for health action and focuses on the way that an individual percepts are motivated toward, and implementation a healthy behavior (16).

The HBM comprises several primary concepts that explain why people will take action to prevent, to be screened for, or to control illness conditions: (1) perceived susceptibility: refers to people's beliefs about the possibility of having a disease or condition; (2) perceived Severity: people's feelings about the seriousness of having an illness or leaving it untreated, which includes the assessment of possible clinical (like death, disability, and pain), and social complications (such as effects of the conditions on work, family life, etc.); (3) perceived benefits: refers to beliefs that the preventive behaviors are useful and effective in reducing the risk or seriousness of the impact; (4) perceived barriers: refers to beliefs about the tangible and psychological costs of the advised action that may act as impediments for undertaking recommended behaviors; (5) Self-efficacy: selfefficacy is defined as "the conviction that one can successfully executes the behavior required to produce the outcomes"; (6) cues to action: contributes to the person's perception of the threat. Cues to action can be internal (e.g., bodily state or symptom) or external (e.g., reminder about doctor's appointment) (17).

HBM has been widely applied as a theoretical framework to explain health promoting behaviors and to guide the researchers in their health behavior interventions (18). Its reliability and validity has been previously approved to identify the beliefs in the field of cervical cancer prevention (19).

\section{Objectives}

This study was performed to identify the determinants of Pap smear screening (PSS) behavior among a group of rural women in Tabriz, Iran, using the HBM model. Identifying the effective factors on PSS may be useful in developing the interventional plans aiming at the promotion of cervical cancer screening behavior.

\section{Methods}

\subsection{Sampling}

This cross sectional study was conducted during September to November 2017 among the rural women referred to the rural health centers in Tabriz, East Azerbaijan province, Iran. Multistage cluster sampling was employed to recruit 220 participants of the study. Two comprehensive health centers were randomly selected out of 5 and the women at the 2 centers entered the study based on their records. The respondents were invited by phone call to participate in the study. When attending the health center, the participants were informed about the research objectives and provided with written informed consent to be signed. Then, the questionnaires were completed in a consultation room in the health center. The women were interviewed to complete the HBM-based questionnaire. Due to nature of the study questions and regarding the culture of the study population, all the interviews were conducted by a trained female interviewer to make participants feel comfort. The inclusion criteria were the rural women, who were not pregnant and had one or more year (s) of espoused life and were consented for participation in this research.

\subsection{Data Collection}

A reliable and valid HBM-based questionnaire was used for data collection (20). This questionnaire was translated into Persian by Karimy et al. to investigate the HBMbased cognitive constructs that relate to Pap smear test in women, who were referred to health centers. In a study carried out by Karimi et al. the Cronbach's alpha was 0.82 for the HBM-based questionnaire and 0.85 for the knowledge. In the current study, the Cronbach's alpha coefficient was 0.76 for the HBM-based and 0.70 for the knowledge questionnaires. The items of the questionnaire were demographic data, comprised age, education level (illiterate/elementary, high school/diploma, university), economic status of the family (weak, fair, good), and history of urinary infection (yes/no). The knowledge scale, which had 12 items, was applied to assess the knowledge of the participants about signs and symptoms of the cervical neoplasm, its severity, and the preventive behaviors. As an example: "Early marriage (at the ages below 17) increases the 


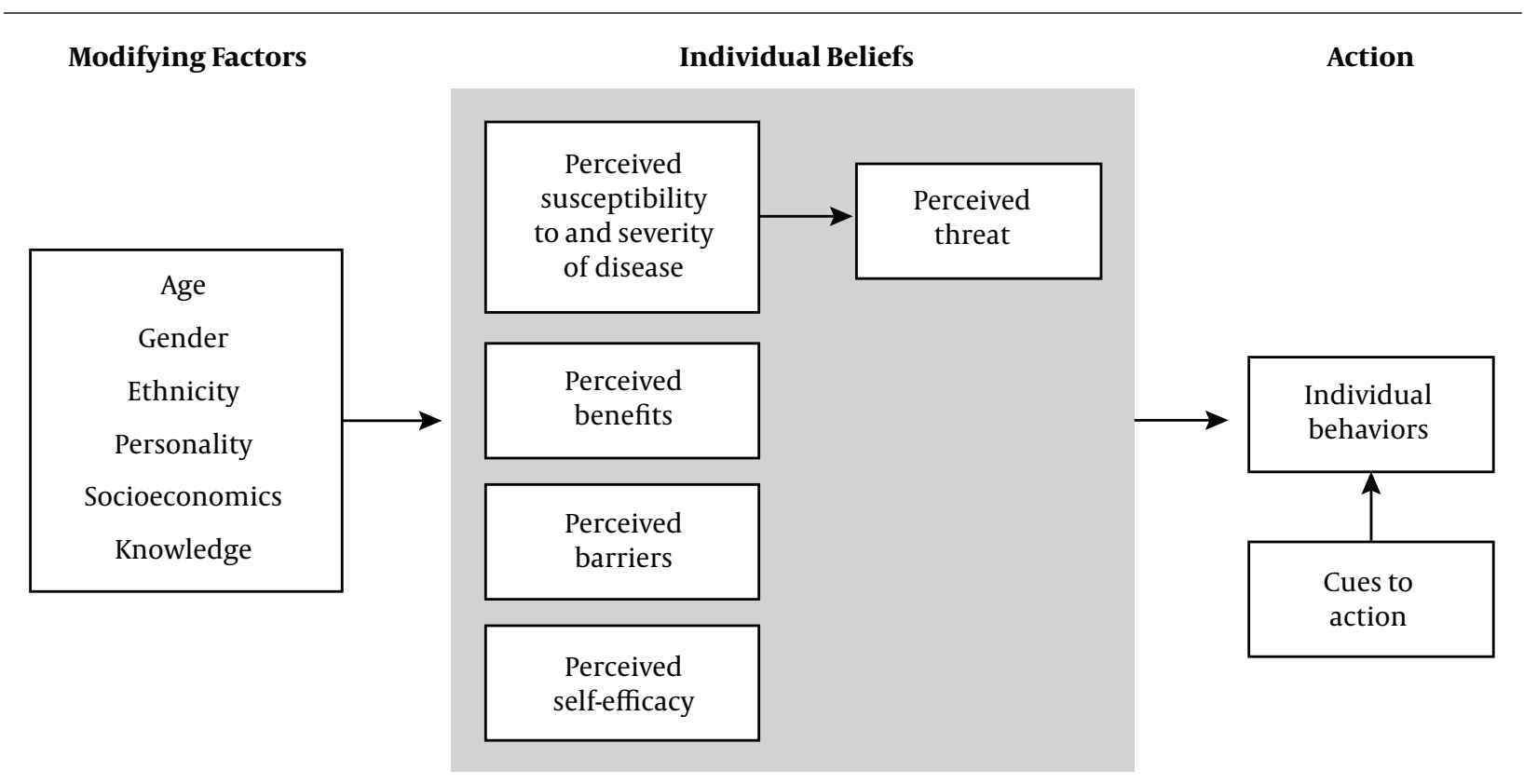

Figure 1. Schematic presentation of health belief model

risk of developing cervical cancer". The answers for each item were yes (2), I don't know (1), and no (0). A 5-item scale was used to measure the perceived susceptibility towards cervical cancer. As an example: "I am worried of being diagnosed with cervical cancer". The perceived severity of the cervical cancer was examined by a 5-item scale, one of which, as an example, was: "The name of cervical cancer causes fear and panic in my mind". There was a 5-point Likert scale for the items of the perceived susceptibility and perceived severity scales ranging from 1 to $5(1=$ totally disagree through $5=$ totally agree). Higher scores indicated more susceptibility and severity towards the cervical cancer.

The perceived barriers and perceived benefits of conducting PSS included 12 items (6 items for each). Two example items of the perceived benefits and perceived barriers were "Having a Pap test will increase the chance of early diagnosis of a possible tumor in my cervix" and "I am too busy to find enough time to go for Pap smear test", respectively. The scoring system of the scales of perceived benefits and perceived barriers was like the perceived susceptibility and severity, as described above. Higher scores on the benefits and lower scores on the barriers were desired.

The scale of self-efficacy to go Pap smear test included 10 items. "I am confident that I can encounter with unexpected problems, effectively" is an example of these items. In this scale, the answers were on a 4-point Likert scale ranging from 1 to 4 ( $1=$ totally confident through $4=$ totally unconfident). Higher scores meant more self-efficacy.
Finally, performing the Pap test was measured, using 1 question: "Have you had a Pap smear test in the previous 3 years?" The answer should be yes (1) or no (0).

\subsection{Analysis}

Data were coded numerically and entered into statistical package for social sciences (SPSS) software version 20 for windows. Summary statistics and frequency distributions were applied to describe and interpret the data. Possible differences in HBM constructs by the demographic variables were examined by One-way ANOVA and the independent samples $t$ test. The associations between HBM constructs and the PSS behavior were analyzed, applying Pearson correlation coefficient test. In addition, logistic regression model with Enter method was used to explain the differences in PSS behavior by the HBM constructs. Shapirowilk test was applied to check the normality of the data with 0.05 level of significance. STATA 11 software was applied to analyze the data.

\section{Results}

The average age, at which the respondents began cervical cancer, was $31.25 \pm 8.81$ years old. Almost all participants were housewives (98.6\%). Regarding the educational level of the participants, 99 (45.0\%) of the subjects were illiterate, $72(32.7 \%)$ had elementary, high schools, and diploma degrees, and 49 (22.3\%) had academic education. Demographic characteristics of the participants are 
demonstrated in Table 1, divided by history of Pap smear test.

As it can be seen in Table 2, there was a statistically significant association assuming the condition of hypothesis Ho a knowledge of rural women, who had and those who did not have a history of PSS in the last 3 years. Moreover, the score of perceived benefits of PSS was higher among those participants, who had a history of PSS in last 3 years $(\mathrm{P}=0.001)$.

The distribution of dependent variable followed the binominal distribution $(\mathrm{P}=0.55)$ and the independent quantitative variables had a linear relationship with the logit of the dependent variables. The fitness of the model was examined by Hosmer-Lemeshow test based on the observed and expected cases in chi-square. The model was fit ( $\mathrm{P}=$ 0.109). To assess the power of the model in classification of the subjects in categories of the dependent variable and the predictability of the model, the classification statistics after logistic was applied. The validity of the model was estimated 69.3\%, which is good.

The results of the univariate analysis showed that the variables of awareness, perceived benefits, and age had significant correlation with performing Pap-smear test $(\mathrm{P}<$ 0.05).

According to the multivariable analysis shown in Table 3 , the odds ratio of age $=0.94(0.91-0.98)$ was statistically significant, so that with one unit increase in age, the odds of cervical cancer screening behavior decreased 6\%. Furthermore, the odds ratio of perceived benefits was 1.18 (1.08 -1.27) i.e. with one unit increase in perceived benefits, odds of cervical cancer screening behavior increased $18 \%$.

Nagelkerke R square for the multivariate model was estimated to be $\mathbf{0 . 2 3 1}$. So, the variables entered in the multivariate model predicted $23.1 \%$ of the pap-smear screening behavior of the participants.

Questions related to barriers of screening Pap test are shown in Table 4. The most important barriers to perform Pap test among the women were "I am in doubt with the efficacy of Pap smear test in detecting cervical cancer" (29.5\%), and "I am afraid of being diagnosed with cervical cancer" (29.1\%), respectively.

\section{Discussion}

Because of the importance of the participation of women in CCS, this study investigated the determinant factors of health behaviors of rural women of Tabriz, Iran in such program. The study found that $55 \%$ of the rural women have participated in PSS in the last 3 years. Lofters et al. reported it 53.1\% (21) in Canada and Sauer reported it 90.5 in US (22), 42\% in California in the past 1 year, and $72 \%$ in the last 2 years (23). The role of rural environment should be considered when talking in this regard. The participation rate of rural women in this study was higher than Kurdish women west of Iran in a study by Aminisani et al. (32\%) (24). It seems that women with specific characteristics had higher participation in CCS: family history of cervical cancer, minor genial infections, high socioeconomic level, higher education (women or their spouses), and universal coverage of primary healthcare in rural areas of Iran (25).

There was a reverse correlation between having CCS and the age of the participants, so that the higher the age of women, the less their intention to perform Pap smear. The study of Silva in urban women of Brazil reported the menopause as the reason for the fall of Pap smear participation (26). Schlichte and Guidry also found that women of higher ages report the test as unnecessary (27). In Canada, the lower participation of women in Pap test was correlated with not being classified in age group of 35 to 49 years (28). In this study, it seems that the higher health literacy of younger women and being in sexually active ages are the reasons for higher participation in CCS. Although women of older cohorts showed less CCS behavior than the younger, it might be due to the cross sectional nature of the study and the cohort effect.

A correlation was observed between the history of urinary infection and the CCS behavior, so that those women with the history of urinary infection had more intention to perform Pap smear. Babazadeh et al. stated the perceived severity of the disease (29) and Karimy et al. (20) stated the fear of disease consequences as the reason for the higher participation of women with urinary infection in the PSS. It seems that these women are more sensitive in follow-up and referral to midwifery services. Yet, the fact that women with the history of urinary infection had more participation in CCS might be, to some extent, due to focus of the health service providers on women in sexually active ages. Moreover, the proper health behavior of these women, compared to those who had not history of urinary infection, shows a good care high risk people. It is also needed to be considered that the history of urinary infection can act as a bias by indication because urinary infection is an indication of CCS.

In this study, no statistically significant difference was observed on the number of Pap smear tests in the last 3 years in terms of economic status of the women. It seems that this finding is related to the nature of the study population, which is consisted of the rural women; because the income inequality within the rural population is low (30). Yet, other studies have reported the effect of economic factors on PSS behavior. A study in Vietnam reported high cost of the PSS and lack of health insurance among the reasons of avoiding PSS in the last 12 months (31). In Canada, the migrant women had lower rate of PSS and those women 


\begin{tabular}{|c|c|c|c|}
\hline Variables & Having Pap Test in Previous 3 Years & Not Having Pap Test in Previous 3 Years & PValue $^{b}$ \\
\hline Age groups & & & 0.001 \\
\hline$\geq 25$ & $54(10.2)$ & $10(44.3)$ & \\
\hline 26 to 35 & $40(48.0)$ & $47(32.8)$ & \\
\hline 36 to 45 & $21(36.7)$ & $36(17.2)$ & \\
\hline $46 \leq$ & $7(5.5)$ & $5(5.7)$ & \\
\hline Level of education & & & 0.806 \\
\hline Illiterate and elementary & $53(43.4)$ & $46(46.9)$ & \\
\hline High school & $42(34.4)$ & $30(30.6)$ & \\
\hline Diploma & $23(18.9)$ & $17(17.3)$ & \\
\hline Bachelor & $4(3.3)$ & $5(5.1)$ & \\
\hline History of urinary infection & & & 0.001 \\
\hline Yes & $27(22.1)$ & $43(43.9)$ & \\
\hline No & $95(77.9)$ & $55(56.1)$ & \\
\hline Economic status of the family & & & 0.060 \\
\hline Good & $32(28.7)$ & $16(16.3)$ & \\
\hline Fair & $68(55.7)$ & $63(64.3)$ & \\
\hline Poor & $19(15.6)$ & $19(19.4)$ & \\
\hline
\end{tabular}

${ }^{\mathrm{a}}$ Values are expressed as No. (\%).

${ }^{\mathrm{b}} \mathrm{P}$ value based on chi-square test.

\begin{tabular}{|c|c|c|c|}
\hline Variables & Mean \pm SD & Mean Difference (Std Error) & PValue $^{\mathrm{a}}$ \\
\hline Knowledge & & $-1.92(0.77)$ & 0.014 \\
\hline No & $25.50 \pm 6.45$ & & \\
\hline Yes & $27.42 \pm 5.06$ & & \\
\hline Perceived susceptibility & & $0.30(0.64)$ & 0.637 \\
\hline No & $15.22 \pm 5.53$ & & \\
\hline Yes & $14.91 \pm 4.03$ & & \\
\hline Perceived severity & & $-0.65(0.62)$ & 0.297 \\
\hline No & $11.73 \pm 5.06$ & & \\
\hline Yes & $12.39 \pm 4.26$ & & \\
\hline Perceived benefits & & $-3.48(0.61)$ & 0.001 \\
\hline No & $9.43 \pm 4.08$ & & \\
\hline Yes & $12.92 \pm 4.87$ & & \\
\hline Perceived barriers & & $1.25(0.80)$ & 0.121 \\
\hline No & $20.81 \pm 5.98$ & & \\
\hline Yes & $19.55 \pm 5.94$ & & \\
\hline Perceived self-efficacy & & $0.40(0.90)$ & 0.654 \\
\hline No & $30.43 \pm 7.10$ & & \\
\hline Yes & $30.00 \pm 6.34$ & & \\
\hline
\end{tabular}

${ }^{\mathrm{a}} \mathrm{P}$ value was calculated based on independent $t$ test.

in lower social classes had lower health literacy, lower social capital, and non-scientific traditional beliefs (32). Thus, it is recommended to put more emphasize on PSS in middle and lower social classes in rural population. Furthermore, according to the Hill's criteria for causation, the socioeconomic status affects the PSS behavior by temporal sequence principles.

The findings of this study showed that women, who had participated in PSS, had higher awareness than those who had not. A study conducted by Allahverdipour and Emami in Iran reported that one-third of the women had low awareness on cervical cancer (33). Another study in China reported that only $32 \%$ of the participants had a reasonable knowledge on cervical cancer (34). The low awareness of the women in most studies conducted in Iran might be due to the lack of a comprehensive educational 


\begin{tabular}{|c|c|c|c|c|}
\hline \multirow[t]{2}{*}{ Variables } & \multicolumn{2}{|c|}{ Univariable Model } & \multicolumn{2}{|c|}{ Multivariable Model } \\
\hline & OR & OR $(95 \% \mathrm{CI})$ & OR & OR $(95 \% \mathrm{CI})$ \\
\hline Knowledge & 1.06 & $1.01-1.12$ & 1.01 & $0.95-1.06$ \\
\hline Perceived susceptibility & 0.98 & $0.93-1.04$ & - & - \\
\hline Perceived severity & 1.03 & $0.97-1.09$ & - & - \\
\hline Perceived benefits & 1.20 & $1.12-1.30$ & 1.18 & 1.08 to 1.27 \\
\hline Perceived barriers & 0.96 & $0.92-1.01$ & - & - \\
\hline Perceived self-efficacy & 1.01 & $0.96-1.06$ & - & - \\
\hline Age & 0.93 & $0.90-0.96$ & 0.94 & 0.91 to 0.98 \\
\hline
\end{tabular}

Table 4. The Frequency of Barriers to Performing Pap Smear Test Among Housewife Rural Women, Tabriz, Iran ${ }^{\mathrm{a}}$

\begin{tabular}{|c|c|c|c|c|c|}
\hline Variables & Totally Agree & Agree & No Idea & Totally Disagree & Disagree \\
\hline I hate such an examination and sampling procedure & $38(17.3)$ & $44(20.0)$ & $56(25.5)$ & $50(22.7)$ & $32(14.5)$ \\
\hline I am too busy to go for having Pap smear test & $22(10.0)$ & $21(9.5)$ & $59(26.8)$ & $69(31.4)$ & $49(22.3)$ \\
\hline If I would have cervical cancer, I prefer not to be aware of. & $27(12.3)$ & $17(7.7)$ & $55(25.0)$ & $63(28.6)$ & $58(26.4)$ \\
\hline Such cancers are the results of fate & $34(15.5)$ & $34(15.5)$ & $43(19.5)$ & $60(27.3)$ & $49(22.3)$ \\
\hline I am afraid of being diagnosed with cervical cancer & $25(11.4)$ & $21(9.5)$ & $48(21.8)$ & $62(28.2)$ & $64(29.1)$ \\
\hline I am in doubt with the efficacy of Pap smear test in detecting cervical cancer & $20(9.1)$ & $30(13.6)$ & $65(29.5)$ & $62(28.1)$ & $43(19.5)$ \\
\hline
\end{tabular}

${ }^{\mathrm{a}}$ Values are expressed as No. (\%).

program for women on cervical cancer and the PSS. Moreover, cultural differences between the societies can be affective on the level of awareness on cervical cancer. A study in Qatar reported women with diagnosed cervical cancer, employed, 15 years and more of married life, academic education, and more than 3 birth giving were most likely to participate in PSS (35). Since the rural women in Iran usually marry in lower ages and had little opportunity for higher education and regarding the fact that $47 \%$ of the participants in this study were illiterate or with low education, there is a necessity for educations on CCS, which should be appropriate for rural culture. Education of the spouses and using the health providers might be other effective interventions (36).

The average score of perceived s of PSS had a significant difference between women, who had and those who did not have the history of CCS. Based on this finding, we can recommend intervention measures for increasing the awareness of rural women about the benefits of PSS to increase their participation in the program. The "perceived benefits" was the only construct of the health belief model that was significant among the rural women. Majority of these women had low age and education. Thus, they might not have an accurate understanding of susceptibility and severity of the cervical cancer and in their opinion, the incidence of the cancer is mostly chancedependent. This means that the behaviors of those women, who were familiar with mechanism and the risk factors of cervical cancer, were more predictable by the health beliefs model. In a study in urban Iran, using the health belief model, the awareness of the women, perceived severity, perceived benefits, perceived barriers, and perceived selfefficacy were the predictors of CCS behavior (37). The fact that other constructs of the model were not significant predictors of the behavior of the rural women might also be due to their little knowledge about the Pap smear. If then, the health workers who promote the Pap smear should rearrange their attempts on rural population.

The situation of the constructs of the health belief model was not good in this study, so that the average scores of the perceived susceptibility and perceived severity among women who had the history of PSS in the last 3 years were higher than those women who did not have. This finding is in line with the study of Allahverdipour and Emami in which $24.9 \%$ of the participants were in a good situation on perceived susceptibility and $32.8 \%$ in a good situation on perceived severity (33). In addition, in the study of Allahverdipour, the perceived benefits and barriers in $47 \%$ of the cases were in a poor situation (33). The perceived barriers in the study of Allahverdipour and the perceived benefits and barriers were the predictors of PSS (33).

The "perceived benefits" in both univariate and multivariate models was a predictor of CCS behavior. In the fi- 
nal model, which showed closer results to the reality, the perceived benefits was the best predictor of PSS in rural women. A negative correlation was also observed between age and the perceived benefits in this study. Women in lower ages usually perceive lower benefits for PSS due to marriage in lower age, lower education, and health literacy. In the study of Hope et al., the perceived barriers, perceived severity, and awareness were the predictors of PSS (38). Another study by Costa et al. reported the perceived benefits and barriers as predictors of PSS behavior among women (39). In a study carried out by Miri et al. in Birjand, Iran, they demonstrated that the perceived benefits $(\beta=$ $0.17, \mathrm{P}=0.01)$, the perceived barriers $(\beta=-0.19, \mathrm{P}=0.01)$, and the perceived self-efficacy $(\beta=0.10, \mathrm{P}=0.01)$ have direct and significant effects on Pap smear behavior. The perceived threat $(\beta=0.002, \mathrm{P}=0.99)$ has no significant direct effect on Pap smear behavior (40).

\subsection{Conclusions}

The use of health belief model in identifying the predictors of PSS among rural women was successful. The awareness and the perceived benefits of the PSS were the most important predictors of CCS behavior. Thus, the health service providers should focus on increasing the awareness of the rural women on cervical cancer, PSS, and its benefits. The barriers of the PSS should be removed and the misconceptions of the women should be resolved. Based on the findings of this study, to increase the participation rate of the rural women in PSS program, the health workers should explain the mechanism of cervical cancer and highlight the benefits of the PSS in its early detection. Yet, other constructs of the model such as susceptibility and severity may not be ignored in the education efforts.

\subsection{Limitations}

One of the limitations of this study is the self-report nature of the participants' data, which might result in overreporting the PSS. Another point to consider is that all the participants of this study were from the Turkic ethnicity, which may limit the generalizability of the results to other ethnic groups. The third point is the possibility of selection bias. Yet, the strength of the study is studying women with no history of hysterectomy.

\section{Acknowledgments}

Authors would like to thank all personnel of health vice-chancellery of Urmia University of Medical Sciences for their cooperation.

\section{Footnotes}

Authors' Contribution: Towhid Babazadeh: Designing the study, conducting the study, administrative support, drafting, and revising the manuscript. Ehsan Sarbazi and Shahram Oliaei: Contributed to the study concept and design, interpretation of the data. Saber GhaffariFam and Hosein Azizi: Designing the study, conducting the study, administrative support, drafting, and revising the manuscript. Arash Shirdel and Parvin MostafaGharabaghi: Contributed to the study concept and design, review and revised the manuscript and approved the final manuscript as submitted.

Conflict of Interests: The authors declare that there is no conflict of interest regarding the publication of this paper.

Ethical Approval: Ethical approval to conduct the study was obtained from the name of institutional was Ethics Committee of the Tabriz University of Medical Sciences (approval number: IR.TBZMED.REC.1397.802).

Financial Disclosure: It is not declared by the authors.

Funding/Support: This study was funded by a grant from the Tabriz University of Medical Sciences. This funding body was not involved in the design of the study, collection, analysis, and interpretation of data, in writing manuscripts or deciding to submit manuscripts for publication.

Patient Consent: The aim of the study was explained to the participants and all of them signed the consent forms and the study was based on the Declaration of Helsinki II. Face-to-face interviews were used to fill in the questionnaires. Each interview lasted 20 to 25 minutes.

\section{References}

1. Smith JS, Lindsay L, Hoots B, Keys J, Franceschi S, Winer R, et al. Human papillomavirus type distribution in invasive cervical cancer and high-grade cervical lesions: A meta-analysis update. Int J Cancer. 2007;121(3):621-32. doi: 10.1002/ijc.22527. [PubMed: 17405118].

2. Torre LA, Bray F, Siegel RL, Ferlay J, Lortet-Tieulent J, Jemal A. Global cancer statistics, 2012. CA Cancer J Clin. 2015;65(2):87-108. doi: 10.3322/caac.21262. [PubMed: 25651787].

3. Bray F, Ferlay J, Soerjomataram I, Siegel RL, Torre LA, Jemal A. Global cancer statistics 2018: GLOBOCAN estimates of incidence and mortality worldwide for 36 cancers in 185 countries. CA Cancer J Clin. 2018;68(6):394-424. doi: 10.3322/caac.21492. [PubMed:30207593].

4. Khorasanizadeh F, Hassanloo J, Khaksar N, Mohammad Taheri S, Marzaban M, H. Rashidi B , et al. Epidemiology of cervical cancer and human papilloma virus infection among Iranian women-analyses of national data and systematic review of the literature. Gynecol Oncol. 2013;128(2):277-81. doi: 10.1016/j.ygyno.2012.11.032. [PubMed: 23200918].

5. Jamdar F, Farzaneh F, Navidpour F, Younesi S, Balvayeh P, Hosseini M, et al. Prevalence of human papillomavirus infection among Iranian women using COBAS HPV DNA testing. Infect Agent Cancer. 2018;13:6. doi: 10.1186/s13027-018-0178-5. [PubMed: 29416557]. [PubMed Central: PMC5784531]. 
6. Chetty R. 70 years of the JCP-highly cited papers: The causal relation between human papillomavirus and cervical cancer. I Clin Pathol. 2017;70(12):997. doi: 10.1136/jclinpath-2017-204867. [PubMed: 29158450].

7. Smith RA, Andrews KS, Brooks D, Fedewa SA, Manassaram-Baptiste D, Saslow D, et al. Cancer screening in the United States, 2018: A review of current American Cancer Society guidelines and current issues in cancer screening. CA Cancer J Clin. 2018;68(4):297-316. doi: 10.3322/caac.21446. [PubMed: 29846940].

8. Patel P, Hari AY, Bernstein M, Farfel A, Raman K. Assessing knowledge of cervical cancer among health care students in Mwanza, Tanzania [90]. Obstet Gynecol. 2018;131:165S. doi: 10.1097/01.AOG.0000533145.45599.2b

9. Teame H, Addissie A, Ayele W, Hirpa S, Gebremariam A, Gebreheat $G$, et al. Factors associated with cervical precancerous lesions among women screened for cervical cancer in Addis Ababa, Ethiopia: A case control study. PLoS One. 2018;13(1). e0191506. doi: 10.1371/journal.pone.0191506. [PubMed: 29352278]. [PubMed Central: PMC5774809].

10. Do HH, Taylor VM, Yasui Y, Jackson JC, Tu SP. Cervical cancer screening among Chinese immigrants in Seattle, Washington. J Immigr Health. 2001;3(1):15-21. doi: 10.1023/A:1026606401164. [PubMed: 16228798]. [PubMed Central: PMC1618776]

11. Farzaneh E, Heydari H, Shekarchi AA, Kamran A. Breast and cervical cancer-screening uptake among females in Ardabil, northwest Iran: A community-based study. Onco Targets Ther. 2017;10:98592. doi: 10.2147/OTT.S125344. [PubMed: 28255244]. [PubMed Central: PMC5322848]

12. Sadjadi A, Malekzadeh R, Derakhshan MH, Sepehr A, Nouraie M, Sotoudeh $\mathrm{M}$, et al. Cancer occurrence in Ardabil: Results of a populationbased cancer registry from Iran. Int J Cancer. 2003;107(1):113-8. doi: 10.1002/ijc.11359. [PubMed: 12925965].

13. Babazadeh T, Nadrian H, Rezakhani Moghaddam H, Ezzati E, Sarkhosh R, Aghemiri S. Cognitive determinants of cervical cancer screening behavior among housewife women in Iran: An application of Health Belief Model. Health Care Women Int. 2018;39(5):555-70. doi: 10.1080/07399332.2018.1425873. [PubMed: 29338646].

14. Plotnikoff RC, Trinh L, Courneya KS, Karunamuni N, Sigal RJ. Predictors of aerobic physical activity and resistance training among Canadian adults with type 2 diabetes: An application of the Protection Motivation Theory. Psychol Sport Exerc. 2009;10(3):320-8. doi: 10.1016/j.psychsport.2008.10.002.

15. Michie S, Abraham C. Interventions to change health behaviours: Evidence-based or evidence-inspired? Psychol Health. 2004;19(1):2949. doi: $10.1080 / 0887044031000141199$.

16. Sundstrom B, Brandt HM, Gray L, Young Pierce J. It's My Time: Applying the health belief model to prevent cervical cancer among collegeage women.JCommun Manage.2018;22(2):161-78. doi:10.1108/jcom-062016-0044.

17. Jones CJ, Smith H, Llewellyn C. Evaluating the effectiveness of health belief model interventions in improving adherence: A systematic review. Health Psychol Rev. 2014;8(3):253-69. doi: 10.1080/17437199.2013.802623. [PubMed: 25053213].

18. VanDyke SD, Shell MD. Health beliefs and breast cancer screening in rural appalachia: An evaluation of the Health Belief Model. J Rural Health. 2017;33(4):350-60. doi:10.1111/jrh.12204. [PubMed: 27545099].

19. Chapman Lambert CL, Azuero A, Enah CC, McMillan SC. A psychometric examination of an instrument to measure the dimensions of Champion's Health Belief Model Scales for cervical cancer screening in women living with HIV. Appl Nurs Res. 2017;33:78-84. doi: 10.1016/j.apnr.2016.09.004. [PubMed: 28096028].

20. Karimy M, Gallali M, Niknami S, Aminshokravi F, Tavafian S. The effect of health education program based on Health Belief Model on the performance of Pap smear test among women referring to health care centers in Zarandieh. Pars Jahrom Univ Med Sci. 2012;10(1):53-9. doi: 10.29252/jmj.10.1.53.

21. Lofters AK, Moineddin R, Hwang SW, Glazier RH. Predictors of low cervical cancer screening among immigrant women in Ontario, Canada.
BMC Womens Health. 2011;11:20. doi: 10.1186/1472-6874-11-20. [PubMed: 21619609]. [PubMed Central: PMC3121675].

22. Sauer AG, Jemal A, Simard EP, Fedewa SA. Differential uptake of recent Papanicolaou testing by HPV vaccination status among young women in the United States, 2008-2013. Cancer Epidemiol. 2015;39(4):650-5. doi: 10.1016/j.canep.2015.05.002. [PubMed: 26055147].

23. Sadler GR, Lahousse SF, Riley J, Mercado B, Trinh AC, Cruz LA. Predictors of breast and cervical cancer screening among Chamorro women in Southern California. J Cancer Educ. 2010;25(1):76-82. doi: 10.1007/s13187-009-0016-y. [PubMed: 20112139]. [PubMed Central: PMC2848334].

24. Aminisani N, Fattahpour R, Abedi L, Shamshirgaran SM. Determinants of cervical cancer screening uptake in Kurdish women living in Western Iran, 2014. Asian Pac J Cancer Prev. 2016;17(8):3763-7. doi: 10.14456/apjcp.2016.167/APJCP.2016.17.8.3763. [PubMed: 27644614].

25. Parsa P, Sharifi F, Shobeiri F, Karami M. Effects of group counseling based on health belief model on cervical cancer screening beliefs and performance of rural women in Kaboudrahang, Iran. Asian Pac J Cancer Prev. 2017;18(6):1525-30. doi:10.22034/APJCP.2017.18.6.1525 [PubMed: 28669162]. [PubMed Central: PMC6373803].

26. Silva L, Miranda A, Batalha R, Ferreira L, Santos M, Talhari S. Highrisk human papillomavirus and cervical lesions among women living with HIV/AIDS in Brazilian Amazon, Brazil. Braz J Infect Dis 2015;19(6):557-62. doi: 10.1016/j.bjid.2015.07.001. [PubMed: 26260194].

27. Schlichte MJ, Guidry J. Current cervical carcinoma screening guidelines. J Clin Med. 2015;4(5):918-32. doi: 10.3390/jcm4050918. [PubMed: 26239455]. [PubMed Central: PMC4470206].

28. Gupta S, Palmer C, Bik EM, Cardenas JP, Nunez H, Kraal L, et al Self-sampling for human papillomavirus testing: Increased cervical cancer screening participation and incorporation in international screening programs. Front Public Health. 2018;6:77. doi 10.3389/fpubh.2018.00077. [PubMed: 29686981]. [PubMed Central: PMC5900042]

29. Babazadeh T, Dianatinasab M, Daemi A, Nikbakht HA, Moradi F, Ghaffari-Fam S. Association of self-care behaviors and quality of life among patients with type 2 diabetes mellitus: Chaldoran county, Iran. Diabetes Metab J. 2017;41(6):449-56. doi 10.4093/dmj.2017.41.6.449. [PubMed: 29272083]. [PubMed Central: PMC5741554].

30. Bao H, Zhang L, Wang L, Zhang M, Zhao Z, Fang L, et al. Significant variations in the cervical cancer screening rate in China by individual-level and geographical measures of socioeconomic status: A multilevel model analysis of a nationally representative survey dataset. Cancer Med. 2018;7(5):2089-100. doi: 10.1002/cam4.1321. [PubMed: 29573569]. [PubMed Central: PMC5943548].

31. Domingo EJ, Noviani R, Noor MR, Ngelangel CA, Limpaphayom KK, Thuan TV, et al. Epidemiology and prevention of cervical cancer in Indonesia, Malaysia, the Philippines, Thailand and Vietnam. Vaccine. 2008;26 Suppl 12:M71-9. doi:10.1016/j.vaccine.2008.05.039. [PubMed: 18945416].

32. Datta GD, Blair A, Sylvestre MP, Gauvin L, Drouin M, Mayrand MH Cervical cancer screening in Montreal: Building evidence to support primary care and policy interventions. Prev Med. 2018;111:265-71. doi: 10.1016/j.ypmed.2018.02.037. [PubMed: 29524453].

33. Allahverdipour H, Emami A. Perceptions of cervical cancer threat benefits, and barriers of Papanicolaou smear screening programs for women in Iran. Women Health. 2008;47(3):23-37. doi: 10.1080/03630240802132302. [PubMed: 18714710].

34. Gu C, Chan CWH, Chow KM, Yang S, Luo Y, Cheng H, et al. Understanding the cervical screening behaviour of Chinese women: The role of health care system and health professions. Appl Nurs Res. 2018;39:5864. doi: 10.1016/j.apnr.2017.09.009. [PubMed: 29422178].

35. Al-Meer FM, Aseel MT, Al-Khalaf J, Al-Kuwari MG, Ismail MF. Knowledge, attitude and practices regarding cervical cancer and screening among women visiting primary health care in Qatar. East Mediter Health J. 2011;17(11):855-61. doi: 10.26719/2011.17.11.855. [PubMed: 
22276494]

36. Keikhaee R, Rakhshani F, Fijan S, Keikhaee M, Rad J, Roostaee F. The effectiveness of oral health education by peers on knowledge and performance of students in Zabol, Iran. Int J Res Med Sci. 2014;2(1):222. doi 10.5455/2320-6012.ijrms20140243.

37. Refaei M, Dehghan Nayeri N, Khakbazan Z, Yazdkhasti M, Shayan A. Exploring effective contextual factors for regular cervical cance screening in Iranian women: A qualitative study. Asian Pac J Cancer Prev. 2018;19(2):533-9. doi: 10.22034/APJCP.2018.19.2.533. [PubMed: 29480997]. [PubMed Central: PMC5980946].

38. Hope KA, Moss E, Redman CWE, Sherman SM. Psycho-social in fluences upon older women's decision to attend cervical screening: A review of current evidence. Prev Med. 2017;101:60-6. doi: 10.1016/j.ypmed.2017.05.002. [PubMed: 28502577].

39. Costa AR, Silva S, Moura-Ferreira P, Villaverde-Cabral M, Santos O, Carmo ID, et al. Cancer screening in Portugal: Sex differences in prevalence, awareness of organized programmes and perception of benefits and adverse effects. Health Expect. 2017;20(2):21120. doi: 10.1111/hex.12450. [PubMed: 26914376]. [PubMed Central: PMC5354027].

40. Miri MR, Moodi M, Sharif-Zadeh GR, Malaki Moghadam H, Miri M, Norozi E. Cognitive predictors of cervical cancer screening's stages of change among sample of Iranian women health volunteers: A path analysis. PLoS One. 2018;13(3). e0193638. doi: 10.1371/journal.pone.0193638. [PubMed: 29558488]. [PubMed Central: PMC5860704]. 